\title{
Thinking on Status and Suggestions for University Biology Laboratory Staff under the Teaching Reform Background
}

\author{
Lili Guan ${ }^{1, \text { a }}$, Zhouyu Jin ${ }^{1, \mathrm{~b}}$, Yuting $\mathrm{Li}^{1, \mathrm{c}}$, Huijing Liu${ }^{1, \mathrm{~d}}$, Xiyan Cui ${ }^{1, \mathrm{e}}$, Hao Dong ${ }^{1 \text {, }}$ \\ fand Haiyan $\mathrm{Li}^{1, \mathrm{~g}^{*}}$ \\ ${ }^{1}$ College of Life Science, Jilin Agricultural University, Changchun 130118, China

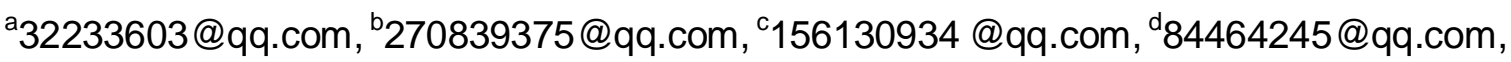 \\ ef174655675@qq.com, ${ }^{\dagger}$ donghao_jlau@qq.com, ${ }^{9}$ hyli99@163.com
}

*The corresponding author

Keywords: Laboratory staff team; Laboratory construction; Common problem; Professional quality

\begin{abstract}
Laboratory team is a very important part of college teachers and also is the backbone of the current laboratory construction and management, so it is the foundation and key for biological experimental teaching work and laboratory construction to build a high-level, high-quality and hard-working laboratory assistant team. Based on analyzing of existing common problems in laboratory team construction as non-perfect system for laboratory team construction and ambiguous role setting for laboratory staffs, this essay puts forward to strengthen the construction of experimental staff to Improve the overall quality of the experimental technical team from following aspects: changing concepts, focusing on works of the experimenter, improving the status of the experimenter and defining their job responsibility, improving the reward and punishment mechanism, improving the professional quality of the laboratory staff, and actively participating in the construction of experimental platform and experimental centers.
\end{abstract}

\section{Introduction}

As an important part of biology teaching, biology experiment class is not only a teaching process for combining theory and practice but also a supplement and deepening of classroom theory, and so it plays a vital role in the process of student's experimental skills development ${ }^{[1]}$. The laboratory staffs are important members of the college teachers, and they are the actual performers and labor's managers $^{[2]}$, so their morality and professional level for business directly impact on the laboratory management and the normal development of laboratory teaching and science research and so as to for cultivating high-quality personnel. The laboratory staffs are important for college teaching and science research ${ }^{[3]}$, and this is much more obvious in practice of high-practical college biology teaching and research.

A good laborer means not only to be a good experimental instrument keeper, but also to be the experimental course attendant, laboratory equipment maintenance staff, laboratory security staff, and even to participate in the reform of experimental teaching and be a researcher of teaching reform $^{[4]}$. However, there still exist many problems and shortcomings in the construction of college biology labors under the Teaching Reform background.

\section{Non-Perfect System for Laboratory Team Construction}

Experimental teaching and laboratory team in the history of higher education in China has always been in a position that is not valued, and experimental staff has been always seen as the second line "teaching staff" for supplementary teaching, and these makes a prejudice in people's 
mind that the laboratory work is insignificant. The traditional idea of "focusing on only theory without experiment" is the reason for not willing to work in the laboratory for many graduate students, especially doctoral students, and at the same time impacts on restricts the construction of the laboratory team. However, in recent years, each of the colleges has set up its own experimental center. The building of this kind of experimental center plays a huge role in promoting the development of the college, and makes the teaching and research teachers be able to put into their own works and at the same time promotes the construction of the laboratory team.

Non-Perfect Laboratory Staff Management and Examination System. In terms of present situation, the construction of the experimental center and the laboratory team is not perfect enough mainly for the following aspects: firstly, the distribution of the workload of the laborers is unreasonable, and the uneven distribution seriously affects the enthusiasm of the experimenter. Secondly, there is no perfect evaluation system for experimenters. The work of the laborers is not like the one of teaching and research teachers which can be used to be quantified by their teaching performance and scientific research, and it is unreasonable for many colleges to make year-end evaluation for experimenters by all staffs' vote because many teachers simply do not understand what the experimenters do or whether they do it well. Consequently, it is urgent priority to establish a reasonable evaluation system. Thirdly, the way of taking instructor as a laboratory director has been changed. Most of the instructor's energy has been put on teaching and research, so that it is difficult to have any energy to deal with the daily affairs of the laboratory, which leading to an unchanging situation of the experimental staffs that is the same as before when there is no experimental center: they need to solve all problems by their own. In addition, the promotion title for experimenters is more difficult, easily pronging to a negative psychology.

Trainings for the Laboratory Team is Weak and the Overall Quality Needs to be Improved.There is a lack of planning and measures of trainings for experimental technicians no matter from the school or from colleges at all levels, consequently, many of the experimental technicians has no chance of getting training in experimental techniques or improving education background and even be difficult to participate in the relevant academic exchange or go out to the brother universities for study. As a result, some experimental techniques that have aspiration of advanced studies are forced to leave from the lab by taking entrance examination for graduate students or doctor students. Meanwhile, this also causes out that the overall quality of many colleges experimental teaching team is not high enough, which is not suit with the current requirements of quality education. Idea and awareness 'hysteresis of some of the experimental staff who as well has lack of knowledge on the importance of experimental teaching and laboratory teams and lack of goal is the subjective reason. With not enough scientific research work, they are all day busy with laboratory teaching and rarely participate in scientific research and so have little scientific research achievement. Moreover, knowing little about the new knowledge and with narrow knowledge makes the experimental teachers have no ability to catch up with the fast updated knowledge.

The Experimenter has an Ambiguous Role and is Lack of Work Enthusiasm.The experimental teaching work is complicated, hard, wide-range involved, and the details can be seen in Table 1. The experimenters shall not only be familiar with the experimental curriculum system, grasp the purpose of each experiment, and do a good preparation for each kind of experiments, but also help teachers to manage the experimental students while managing the equipment and keeping properties safe is their daily work. The laborer's work which is known as easy by so many other people is actually trivial and hard, and the non-recognizing of their work undoubtedly seriously dampens the experimenters' working enthusiasm. The fuzzy role and complicated work makes the 
young laborers be confused, that they can't find the direction of progress and have neither professional identity nor sense of accomplishment and are lack of work enthusiasm; in addition, the idea of vague definitions from school about the laboratory's tasks, status, connotation and function is at the same time spreading throughout the broad masses of young teachers, that their experimental teaching efficiency and effect is terrifically influenced. In consequence, the laborers' work efficiency has a low level of work efficiency overall.

Table 1 Duties of undergraduate laborers

\begin{tabular}{|c|c|c|}
\hline $\begin{array}{l}\text { Sequence } \\
\text { numbe }\end{array}$ & Laboratory management & Auxiliary experiment teaching \\
\hline 1 & $\begin{array}{l}\text { Laboratory safety } \\
\text { management }\end{array}$ & $\begin{array}{l}\text { To prepare for experimental class opening at the } \\
\text { request of the experiment teachers }\end{array}$ \\
\hline 2 & $\begin{array}{l}\text { Laboratory hygiene } \\
\text { management }\end{array}$ & $\begin{array}{l}\text { To assist the experiment teachers with Preliminary } \\
\text { experiments }\end{array}$ \\
\hline 3 & $\begin{array}{l}\text { Laboratory low-value } \\
\text { materials and other goods } \\
\text { and materials management }\end{array}$ & $\begin{array}{l}\text { To guide students in the experiment for the use of } \\
\text { instruments and equipment, and get ready to deal } \\
\text { with emergency }\end{array}$ \\
\hline 4 & $\begin{array}{l}\text { Laboratory instruments and } \\
\text { equipment management }\end{array}$ & $\begin{array}{l}\text { To clean the lab in a timely manner after the } \\
\text { experimental class and make preparation for the next } \\
\text { experiment }\end{array}$ \\
\hline 5 & $\begin{array}{l}\text { Laboratory information } \\
\text { management }\end{array}$ & $\begin{array}{l}\text { To comprehensively guide students doing } \\
\text { experiments related experiment technology and } \\
\text { equipment use while opening laboratory without } \\
\text { experiments class }\end{array}$ \\
\hline 6 & $\begin{array}{l}\text { Laboratory open } \\
\text { management }\end{array}$ & $\begin{array}{l}\text { To participate in the experimental teaching } \\
\text { reformation and experiment project innovation } \\
\text { hosted by laboratory teachers }\end{array}$ \\
\hline 7 & $\begin{array}{l}\text { Laboratory development } \\
\text { planning and construction } \\
\text { management }\end{array}$ & $\begin{array}{l}\text { To timely maintain and repair the equipment and } \\
\text { keep intact rate of them }\end{array}$ \\
\hline
\end{tabular}

The work enthusiasm of young laboratory technician in local colleges is generally low, and most of the technicians are not actively take part in experiment (practice) teaching activities. Here are the reasons: at first, both the school and technicians themselves have not enough knowledge on the importance of experimental teaching; secondly, they can't catch up with full-time teachers in respect of salary and title assessment, and this cause out confusion about their personal development and a lack of working initiative; thirdly, there is no related encouragement policies that it is the same whether they do little or many works, which restricts their work enthusiasm and affects the team stability; fourthly, even if there are some advanced ideas of innovation, they cannot apply for all kinds of scientific research funds at the same level with full-time teachers.

The present work situation of young experimenters in local colleges and universities is not conducive to the reform of colleges and universities and even more to the development of the school. Only if the relevant rules and regulations be constantly improved and an effective incentive mechanism is set to stimulate the initiative and creativity of young experimenters, they would play the role as a main force in the transformation of university laboratories. 


\section{Thinking on Undergraduate Biological Laboratory Assistant Team Building}

With the rapid development of biotechnology in recent years, biology experimental equipment becomes more and more high-end and the new technologies and equipment and the actual requirements of the current experimental teaching reform needs them to have a higher overall quality and experimental skills. Therefore, to enhance the quality of the experimental team plays a crucial role for experimental teaching.

To Change the Concept, Pay High Attention to the Experimenter'S Work and to Improve the Status of the Experimenter. The old idea about experimental staffs is the biggest obstacle to the construction of the laboratory staff team. First of all, it needs to use a development view to re-understand about their work. The laborers were once engaged in some trivial work without technical content, such as preparing drugs, glass instruments, etc., and they were not given enough attention in the construction of colleges and even were marginalized. They were thought as accessories in the teaching process. Paying no attention on the construction of the laboratory staff team is to a large extent makes the experimental work deviate from the right direction and hits their enthusiasm, which makes many labors have a negative idea "less or more is the same". However, the quality of labors is quickly improving. Duties in the team are subdivided: some are responsible for the basic course and some for large-scale instrument testing. In addition, the laborers 'role is changing thanks to the development of science and technology and the increase investment to laboratories in school.

Second, we should pay attention to the work of the laboratory assistants. The lack of attention to the work of the lab staff has led to the lack of attention to the laborers. Through the whole process from emphasizing on teaching to emphasizing on both teaching and scientific research, colleges and universities always focus only on teaching performance and scientific research but less on the work of the experimental staff. It is undeniable that the teaching performance and scientific research results has brought a reputation to the school, but the vast number of laborers also put much of their hard working into the obtained teaching performance and scientific research of the full-time teachers. As a part of supplementary teaching staff, they have deeply got involved in college teaching and scientific research in all aspects and have provided a strong guarantee to the improvement of teaching quality and the training of practical talents for the community. So, schools should give their confirmation to the importance of laborers' work and keep trying to change the idea under the majority of teachers that the laborer 'work is not important.

To Define the Job Responsibilities and Sound the Reward and Punishment Mechanism. Making definition about the job responsibilities of the laborers is the premise for them to do a good job. At this point, it must seek truth from facts, make the task clear and fully reflect the purpose of this post of experimental staff, to minimize the homogeneity requirements with the full-time teachers and to make it different from laboratory management, scientific laboratory laboratories and large equipment management. Only in this way can we highlight the focus and ensure the efficient and normal operation of undergraduate laboratories.

Colleges should increase the laborers' salary to make them work with a peace mind because it is generally lower than the one of teachers and there is no other way for them to get payment. The following aspects of measures can be done to increase the salary: firstly, to mobilize the enthusiasm of the experimental staff by providing experimental preparation fee to laborers in basal laboratory and taking out part of the experimental test to laborers in open laboratory; secondly, to implement overtime pay for them instead of the previous policy of non-overtime payment; thirdly, to implement post Salary System which means to set up some experimental technical positions and employ some laborers with outstanding performance and skills who can get some post allowance. 
Schools should gradually improve the wages of laborers to stabilize the experimental team and to mobilize the enthusiasm of the experimental staff, and also should set up a clear incentive mechanism and an internal assessment work to give excellent labors both material and spiritual incentives.

Enhance the Professional Quality of the Laborer Team. Local college transformation needs much more versatile talents with high technological content, strong innovative thinking and comprehensive ability. The young laborers should try hard to become this kind of talents in order to suit the development and needs in transforming period. Experimental work which is not a simple manual labor but innovative experiment or design experiment or large-scale instrument needs the experimental staff to learn continuously to get new knowledge ${ }^{[5]}$. As for respect of the young laborers themselves, they shall uphold correct concept of self-development and find their own value to promote a virtuous work cycle. And for another aspect of local colleges in transformation period, they shall be as the incubator for the re-positioning of the young experimenter to create a professional environment for them to development, and truly promote the teaching quality and the cultivation of applied talents. First of all, encourage the laborers to study further. The further studies can promote their self-quality and make them better understand the test principle of the instrument by participating in tutor's subject research. Secondly, broaden the development space of young laborers. The school can expand the laborers' horizons and improve their quality of business by hiring some relevant experts inside and outside school to give lectures, sending them to visit high-level institutions and research institutions or providing short-term practice. Thirdly, the school can set up a special research fund to stimulate young researchers' passion on scientific and technology research and thoroughly exert their potential.

To Actively Participate in the Construction of Experimental Platform, and Experimental Centers. To establish school-level and provincial-level experimental platform has become a trend in the development of colleges and universities. The school has need of establishing variety of experimental platforms because a large number of scientific researches need a variety of high-end equipment to test and evident. In general, the school-level experimental platform is operated and managed by specialized laboratory technicians; while the faculty-level experimental platform is managed part-timely by teachers who have multiple identities as both teacher and scientific researchers due to the lack of professional technical staff in respect of the experimental. It is hard for the teacher to use all the energy in the experimental platform management, which resulted in a waste of resources ${ }^{[6]}$. So, the schools need to reference and learn the construction experience of the domestic first-class university experimental platform, especially the faculty-level experimental platform manage model in order to train qualified experimental technicians for the position. And if we regard the experimenters as an important part of the experimental platform in the process of building the form, it will be beneficial for integrating the laborers into the scientific research and making them efficiently participate in the scientific research work of the teachers and the scientific research and construction of the school.

In conclude, the construction of college laboratory staff is the core for strengthening the experimental teaching team and the basal basic assurance for enhancing the undergraduate innovation ability and comprehensive scientific research ability, so it needs to change the concept to pay attention to the work of the experimenter and improve the status based on the actual development of institutions to enhance their enthusiasm; it needs the school to make the laboratory job responsibility clear and the reward-punishment mechanism improved and at the same time to let them participate in the construction of experimental platform and experimental platform to improve the teams' professional skills to meet the needs of current college biology experimental teaching. 


\section{Acknowledgements}

This research was supported by the School-level research topic of Jilin Agricultural University (Grant No.2015xjyb02) and Academic Postgraduate Course Construction of Jilin Agricultural University

\section{Reference}

[1] X Huang and K.H L, Research and Practice on Curriculum Reform of Mathematics Education of College Teacher Based on New Mathematics Curriculum Standard, Journal of Chongqing Normal University: Natural Science Edition, Vol. 26(2009)No.3, p. 115-118. (In Chinese)

[2] Y.Q Hu and X.Y Wang, Problems and Countermeasures in the Construction of Experimental Team of Medical College, Journal of Laboratory Research and Exploration, Vol.32(2013)No.12, p. 234-235. (In Chinese)

[3] X.H Zheng and A.R Zheng, Strengthen the construction of experimental technical team to promote the construction and development of laboratory in colleges and universities, Laboratory Research and Exploration, Vol. 30(2011)No. 9, p. 335-336. (In Chinese)

[4] D.F Huang, H.J Li and Y.H Zhu, Measures to Improve the Quality of Experimental Teaching, Laboratory Research and Exploration, Vol.29(2010)No.2, p. 120-122. (In Chinese)

[5] J.Y Jiang, Talking on How to Improve the Comprehensive Quality of College Laborers in the New Period, China Electronic Commerce, Vol. 5(2014), p. 149. (In Chinese)

[6] X Zhang, Viewing the Work of College Labs with Scientific Development, Experimental Technology and Management, Vol. 28(2011)No. 7, p. 290-294. (In Chinese)

[7] Z.J Yu, N Dong, S.G Liu, M.S Du, W Liu, Y.H Tian and J.Z Liu, Thoughts on the Construction of the Technician Auxiliaries for Biological Undergraduates of University, Experiment Science and Technology, Vol.13(2015)No.2, p. 173-175. (In Chinese)

[8] S.G Liu, X Zhang and N Dong, Thoughts on the construction of laboratory technicians team of biological experiment center, LABORATORY SCIENCE, Vol.15(2012) No. 1, p. 9-11. (In Chinese)

[9] X.A Xia and S.J Huang, Construction of Laboratory Technician Team in Experimental Biology Center of Wuhan University, RESEARCH AND EXPLORATION IN LABORATORY, Vol.30(2011)No.9, p. 258-260. (In Chinese)

[10]B Wang and W Zhou, Construction and Exploration of Laboratory Team in Colleges and Universitie, RESEARCH AND EXPLORATION IN LABORATORY, Vol.32(2013)No.17, p. 203-205. (In Chinese)

[11]Z.G Yao, Strengthening the Construction of the University Laboratory Staffs, Experiment Science and Technology, Vol. 11(2013) No.3, p. 153-155. (In Chinese) 